\title{
Analysis of Pragmatic Failures of Chinese English Learners
}

\author{
Nana Zhang \\ Yantai Nanshan University \\ Yantai, Shandong, China
}

\begin{abstract}
The cultivation of pragmatic competence plays an important role in English learning. Proficiency in grammar knowledge does not ensure appropriate use of language. Devoid of pragmatic competence will certainly lead to pragmatic failure. Analyzing the pragmatic failures of Chinese English learners, this paper aims at finding out the weak points in English learning and trying to solve them. Chinese English learners' pragmatic competence is not of a high level; most pragmalinguistic failures are the misuse of customary phrases, especially those whose meanings are quite different between English and Chinese; sociopragmatic failures are mainly caused by cultural differences. At the end of the paper, suggestions about improving pragmatic awareness, enriching pragmatic knowledge in teaching, etc. have been proposed, in order to reduce pragmatic failure and improve Chinese EFL learners' pragmatic competence.
\end{abstract}

Keywords-pragmatic failure; pragmalinguistic failure; sociopragmatic failure; pragmatic competence

\section{INTRODUCTION}

Nowadays, the use of English and its social function are becoming more and more important. So efficiency in communication is highly required. But many EFL learners use English inappropriately due to the lack of English cultural background, restrictions on language environment, is understanding of western culture, etc. But pragmatic failure is avoidable if we pay more attention to it.

In the early half of 20th century, the subject of linguistics was mainly about linguistic knowledge instead of pragmatic knowledge. The focal point in learning or teaching English had always been linguistic knowledge. In 1972, A merican social linguistician Hymes stressed in his work On Communicative Competence the necessity of pragmatic competence. From then on, people began to realize the importance of pragmatic knowledge.

Cross-cultural communicative competence put forward by Widdowson [1] includes two aspects: linguistic competence and pragmatic competence. Linguistic competence is made up of three components - phonology, lexicon, and grammar, and pragmatic competence, the other important component of communicative competence, is the ability to select a linguistic form that is appropriate for a specific situation, or to use the language appropriately in specific social interactions.
Thomas[2] defines pragmatic failure as "the inability to understand what is meant by what is said." Prag matic failure may lead to incomprehension, misunderstanding, communication breakdown, and, at worst, insult. When communication is carried on in a foreign language, the chances of pragmatic failure will be even higher because the speakers face both linguistic and cultural barriers. Thomas reveals two types of pragmatic failure leading to misunderstanding between language learners and native speakers of the target language. The first type is what she calls "pragmalinguistic failure" and the second "sociopragmatic failure".

In China, Thomas' theory has been widely accepted. Following Thomas's investigation of nonnative speakers' pragmatic failure, scholars in China, such as Huang Cidong, He Ziran, Wang Dexing, and others have done much concerning the pragmatic competence of English language learners in China. One common conclusion they come to is that the learners' general pragmatic competence is of poor level. Based on the researches on pragmatic failure, Chinese scholars devote themselves to avoiding pragmatic failure and promoting pragmatic competence. The studies on pragmatic failure are mainly about classification of prag matic failures, explanation of sources of pragmatic failures, and implications for the instruction of English as a foreign language. According to Yang Qian[3], the studies on pragmatic competence includes the definition and connotation of pragmatic competence, theoretical discussion on the ways of raising learners' pragmatic competence and pragmatic development integrated with English class. One of the most famous linguists of China, He Ziran[4] defines pragmatic competence as the ability of using language appropriately in practical communication, which focus on two aspects: the ability to produce appropriate language and at the same time to interpret correctly what the speaker says according to the speech context.

Through the analysis of categories and reasons of pragmatic failure, this paper tries to expose the present situation of Chinese EFL learners' pragmatic failure, find out solutions toward the problem, so that pragmatic competence can be improved.

\section{ClasSIFICATION OF PRAGMATIC FAILURE}

As introduced above, this section is about the details of pragma-linguistic failure and socio-pragmatic failure. 


\section{A. Pragma-linguistic Failure}

Pragmalinguistic failure is caused by the difference between two languages, i.e. a kind of misunderstanding to pragmatic intention. Speakers usually apply their habits formed in mother tongue to target language. Here is an example. A lady gets lost in America, and she must ask for help. She greets others with "Hi", but it doesn't work. According to American custom, she should begin with "Excuse me" and then tell others what problem she has. Usually "Hi" is an expression used by indecent women. Obviously the lady makes prag malinguistic failure by using wrong expression.

\section{B. Socio-pragmatic Failure}

Sociopragmatic failure, which is related to the speakers' social status, the field of communication,etc, is owing to uncomprehension of cultural background differences between two languages. For example, "Thank you" has the same meaning both in Chinese and in English. But the usage of it is a problem. A Chinese girl may react "No, not at all" if someone praise her beauty according to Chinese idiomatic usage. But an American girl will accept with a big smile. That is the difference of the two languages.

Of course, the distinction of the two types is not absolute. Context, intention, and understandings toward partner's words may be different. According to He Ziran's [5] opinion, some unsuitable expressions may be prag malinguistic failure on the one hand but sociopragmatic failure on the other hand.

\section{ANALYSIS OF PRAGMAT IC FAILURE}

Pragmatic failures exist widely in English learning. But what is the reason? Which kinds are mainly faced by Chinese EFL learners? And what can we do to avoid them? The following statement tries to find the answer.

\section{A. Causes of Pragmatic Failure}

The affection of one's mother tongue in learning a foreign language is called pragmatic transfer. That means using the expression of mother tongue in the target language. There are two kinds of transfer: "positive transfer and negative transfer"[6]. It is still unknown whether the former relates to universal pragmatic knowledge or reflects people's pragmatic competence. The later exists everywhere in language study. According to Yao Zhiying [7], the main reason of pragmatic failure is pragmatic transfer, which includes inter-lingual transfer, intra-lingual transfer, cultural transfer, and different thinking patterns.

1) Inter-lingual Transfer: Inter-lingual transfer means firstly mother tongue transfer, especially negative transfer. Differences exist between mother tongue and target language. Usually speaking, the more the differences are, the easier we are to make pragmatic failure. Take "old" for example, Americans are afraid of being old, so "old" is a taboo. They use"senior citizens" to substitute "old". They express the meaning of old without using "old" itself. But it is a virtue to hold old people in esteem in China. We would say "Zhang
Lao", "Lao Ban", and "Lao Jiaoshou" to show our respect. If we don't know the difference we'll make mistake.

The other aspect is to misunderstand the utterance meaning. For example, Joyce is talking to her friend Brenda: "I wonder if you'd mind posting this letter for me on your way home?" Right answer is "Yes, sure", but Chinese English learners usually respond "You're welcome" or "I don't mind". Let us look at another example: A says: "Could you pass me the salt", and B answers: "Yes, I can." Let's suppose A is an English-speaking man, and B is a Chinese who is leaning English. Generally A knows that B has the ability of passing the salt, and his purpose is to ask B's help. Of course B's answer is right in grammar. But it is a pragmatic failure, because B misunderstands A's pragmatic intention. In the above examples, it is obvious that Chinese English learners are weak in prag matic competence because of inter-lingual transfer.

2) Intra-lingual Transfer: Intra-lingual transfer is produced by the influence of target language. Such as, "These mans are from Britain.", "He goed to the classroom." This is because the learners apply certain principles to every condition. It is called over generalization. In many cases, the plural form of a noun is to plus " $\mathrm{s}$ ' in the end morpheme. Learners may regard this as a fixed principle and "mans" is created. It is the same with "goed".

Sentence pattern also reflect intra-lingual transfer besides words. For example, Chinese tend to use a complete sentence instead of an ellipsis sentence. It is believed that the more complete the sentence is, the clearer the meaning is. So when a foreign teacher asked: "Have you finished your paper that I recommended last week?" A Chinese student would probably answer: "Yes, I've finished your paper that I recommended last week." It sounds lengthy and as though the student is forced to finish the paper.

3) Cultural Transfer: To master a language, it is necessary to know its knowledge, such as grammar and pronunciation, sentence structure, etc. Besides, we must take its usages in every environment into account. Dai Weidong and Zhang Hongling[8] pointed out that cultural transfer occurs when people use their own cultural criteria and values to guide their behavior and thoughts, and to pass judgment on others' behavior and thoughts. Cultural transfer usually brings about misunderstanding and even hatred in communication. So one must be good at cultural characteristics of English.

For instance, when introduced to an old professor or a friend's parents, what would one say? It is polite to say "Nice to meet you" and then shake hands. But quite a few Chinese English learners may respond "How are you". It's very stupid to a native speaker and it seems Chinese only know such kind of simple sentences.

What's more, body languages in different countries have different meanings. With one's thumb up, Americans and Europeans want to take on a bus, but Australians regard it as a kind of insult. In Japan, it stands for number five, while in Germany number one. While Chinese use the gesture to 
praise others. It is important to learn more cultural background knowledge in order to avoid pragmatic failures.

4) Different Thinking Patterns: One's thinking pattern is quite different from others' because of the different cultural backgrounds. When describing a healthy strong man, Chinese would use "cattle". But westerners will say "as strong as a horse". Some learners make mistakes on fixed expressions quite easily. The thinking pattern of Oriental is comprehensive, while westerners would analyze a question from various angles. So it causes "false borrowing"[9]. Therefore in the process of study, the two methods shouldbe combined together, so that the possibility of pragmatic failure will be decreased.

\section{B. Common Pragmatic Failures Committed by Chinese English Learners}

In daily cross-cultural communication, any kinds of pragmatic failures may occur. In this section, five kinds of pragmatic failures would be introduced: addressing, greeting, phatic communication, thanks and apology, and courtesy. Through the description of them, the paper hopes to draw people's attention to the serious problem and avoid them in communication.

1) Addressing: The selection of addressing can affect the communication directly. Polite addressing brings the addressee a good impression. One example would be name. Chinese put surname in the first place, then the given name. While, westerners put given name in the first place and surname the second place. Chinese people use "father", "mother", and "sister" to show respect when calling their family members. But it is common to call each other's name in western families.

A typical example is the addressing of teacher. If a teacher's surname is Liu, his students would call him Teacher Liu. This is not in line with Americans' habit. Teacher is a kind of profession, and can't be used in addressing. Proper use should be "Mr. Liu" or "Miss Liu". Only few professions and positions can be used as addressing, such as Doctor , Governor , Mayor , Professor , etc.

2) Greeting: Greeting is a style of communication. The difference between Chinese and English culture makes greeting styles differently. Westerners seldom refer to privacy in greeting. They say "Hi" "Hello" "How are you" instead. While it is totally beyond the understanding of a Chinese English learner that native speakers would be annoyed when they're addressed "where are you going?" which is a common ly addressing among the Chinese.

In Chinese, age, weight and appearance are all topics of greeting, however, westerners never say so. Chinese may show his concern to a pale-looking man: "You look so pale, are you sick?" Westerners will feel disgusted with such kind of sentence. In their opinion, it is their secret which should not be opened to others. While it's OK to talk about weather, political affairs, etc. As an English learner, one should be aware of the difference in order not to make pragmatic failure.

3) Phatic Communication: Phatic Communication is the beginning of a communication. Its social function is to regulate interpersonal relationship. Westerners get used to talk about weather. "What a nice day!" "It's a fine day, isn't it?" They are not really concerned with weather but it is a habit to begin their talking with weather. Without knowing this, Chinese learners usually use Chinese logic to ask "How many members are there in your family?" "How many money do you earn one month?" Westerners think that these sentences involve their privacy and will be irritated.

When a guest comes from far away, Chinese often say "I'm afraid you must have had a tiring journey." Westerners will be uncomfortable to this sentence, for they'd like to say "Did you have a good trip?" or "How was the trip?" When the guest is going to leave, Chinese host often say "Walk slowly!" But westerners will get angry, "I'm healthy, why should I walk slowly?" So when communicating with foreigners, one must pay attention to the difference between customs.

4) Thanks and Apology: There are certain occasions in daily life where one should react politely, such as expressing thanks and offering apology. They usually have established expressions. In order not to make prag matic failure, one must be acquainted with the cultural differences, language forms and special contexts.

The function of apology is to correct an impolite behavior and recover the relationship between the speakers. The correspondent sentence "It doesn't matter" in English is usually used to accept others' apology by Chinese people. Actually it is improper. Appropriate response should be "That's all right" "That's OK" "No problem". What's more, "Never mind" can't be used to make modest remarks when others appreciate our work. According to He Ziran, "It is a polite idiom to show our acceptance to the partner's apology" (He Ziran, 1997).

In response to others' service, e.g. "Will you have a cup of coffee"? Chinese will use "Thank you" to accept it, but the correct answer should be "Yes, please" or "No, thank you". The ambiguous answer "Thank you" will puzzle the English speakers.

5) Courtesy: When being praised, westerners and Chinese will react differently. Let's look at the following example. A foreign teacher praises his student: "Your English is very good." Westerners will use "Thank you" as an answer. While Chinese regard this answer as immodest, instead they will say "No, no. My English is poor." Because modest is a virtue in Chinese culture, but it is less of confidence in English.

Suppose there is a Chinese woman in America. An American says to her: "Your clothes are so beautiful." She is quite happy inside but answer: "It's just a common one bought in China" in Chinese habit. Then the American may feel himself not a good appreciator in the woman's eyes. To 
the woman, it is far from her intention to what she really wants to express.

\section{SUGGESTIONS ON IMPROVING PRAGMATIC COMPETENCE}

Those who have higher linguistic competence does not necessarily have a high prag matic competence. Excellent in phonetics and grammar does not mean success in crossculture communication. Linguistic competence is not in direct proportion to pragmatic competence. Thus, pragmatic competence must be paid more attention to. Both grammar error and pragmatic failure can lead to failure in communication. But Thomas (1983) pointed out "Grammar errors express the information that the speaker lack of sufficient language knowledge, and such kind of errors can be forgiven. But pragmatic failure tells us that the speaker has many demerits and his behavior will be regarded as boorish or malicious." Foreigners usually can bear grammar errors but not pragmatic failure. Therefore, in the process of English learning, one must pay attention to the following contents.

\section{A. Holding a Proper Attitude toward Failure}

Failure makes one progress. One tumbled down many times before he could walk. It is the same with pragmatic failure. Nobody would master a language without making failures. For example, a young kid says "Tom catched a bird". This is a wrong sentence in grammar. But after hearing it, the kid's parents will be glad because the kid is learning. Of course parents will teach him the past tense of "catch" is caught. The kid memorizes it and next time he won't make the same failure. It could be seen from this example, failure is a necessary procedure in the process of learning. Once there is failure, others will help correcting it. The man who never makes failures cannot learn a language thoroughly.

\section{B. Enriching Knowledge about English Culture}

Grammar is an important part in English learning. Besides, one must be acquainted with relevant background knowledge, such as politics, economy, culture, religion, custom, and so on. It is proposed that Chinese English learners should read large amount of English original works to get familiar with the language. And to watch an English movie is also a good way to learn knowledge. Large amount of background knowledge makes one succeed in communication.

\section{Enhancing the Output of English}

Many Chinese can learn English very well in the paper, but are weak in oral communication. The phenomenon of "dumb English" is universal among Chinese. As a foreign language learner, one should listen more, read more and the most important is to talk in English. It seems that most learner lack exercises. Prag matic competence should be enhanced in communication.

\section{Reducing Pragmatic Failure through Cultural Comparison}

Thinking patterns of Chinese and English are different. Chinese is inclusive, i.e. from specific to general; but English is deductive, i.e. from general to specific. Chinese people advocate modesty and conservation, but English people advocate bluntness and straightforwardness. Chinese people put tradition in a high place, but English people turn up their noses at tradition. Most English learners still need improvement in this aspect.

\section{CONCLUSION}

In communication, pragmatic failure is an unavoidable phenomenon. It is necessary for English learners to recognize, classify and analyze pragmatic failure, then find out the reasons of it. Based on the weaknesses of pragmatic competence and the possible pragmatic failures, the paper further proposes some pedagogical suggestions. It is expected to help English learners reduce pragmatic failure and enhance pragmatic competence. The final purpose is to improve pragmatic competence and to use English skillfully.

\section{REFERENCES}

[1] Widdowson, H.G. 1989. Explorations in Applied Linguistics[M]. Oxford. U.P.

[2] Thomas, J. 1983. Cross-cultural Pragmatic Failure[J]. Applied Linguistics.

[3] Yang, Qian, 2006. An Investigation of the Non-English Major's Pragmat ic Competence[D].Ji Nan: Shandong Normal University.

[4] He Ziran, 1997, "pragmatics and English learning" [M]. Shanghai: Shanghai foreign language education press.

[5] He Ziran, 1988, "introduction to pragmatics" [M]. Changsha: Hunan Education Press.

[6] Ran Yongping, 2006, "pragmatics: phenomenon and analysis" [M]. Beijing: Peking University press.

[7] Yao, Zhi-ying. 2005. Analysis on the pragmatic errors of Chinese college students http: // dlib. cnki. Net / kns 50 / detail. aspx? Query ID $=130 \&$ CurRec $=1($ accessed 05/01/2016)

[8] Dai Weidong, Zhang Hongling, 2002, Cultural Transfer in Foreign Language Communication and Its Enlightenments of Foreign Language Teaching Reform [J], "Foreign Language World" Periodical II

[9] Zhou, Jia-qiu. 2001. An Analysis of the Pragmatic Failures of Chinese Students http: // dlib. cnki. net / kns 50 / detail. aspx? Query ID $=69 \&$ CurRec $=3($ accessed 05/01/2016) 